\title{
Chemical Properties, Antioxidant Activities and Sensory Evaluation of Berry Vinegar
}

\section{Wilawan BOONSUPA}

Department of Biology, Faculty of Science and Technology, Rajabhat Maha Sarakham University, Mahasarakham 44000, Thailand

(Corresponding author's e-mail: wilawanboonsupa@ymail.com)

Received: 25 October 2017, Revised: 28 April 2018, Accepted: 16 May 2018

\begin{abstract}
This study was carried out to examine the chemical properties, antioxidant activities and sensory scores of berry vinegar produced from 4 berry species, namely Morus alba L. (Mulberry), Vaccinium macrocarpon L. (Cranberry), Rubus idaeus L. (Rasberry), and Rubus laciniatus L. (Blackberry). Berry vinegars were produced via a 2 -stage (alcoholic and acetous) fermentation process. The initial soluble solid contents in the berry juice were adjusted to $22^{\circ}$ Brix before the fermentation. Alcoholic fermentation was conducted using Saccharomyces cerevisiae as the inoculant while Acetobacter pasteurianus was used for acetous fermentation. As observed for all samples during the alcoholic fermentation the levels of soluble solids decreased continuously and the levels of alcohol were found to increase at the end of fermentation process. Notably, the wine produced from 'Blackberry' species exhibited the highest levels of alcohol $(11.73 \%)$ while those produced from 'Mulberry' exhibited the highest levels of antioxidant activity $(60.85 \%)$. Similar results were observed for all samples during the acetous fermentation, in which the levels of alcohol dropped continuously and the levels of acetic acid were noted to elevate at the end of the fermentation process. The highest levels of acetic acid (5.01\%) was detected in the vinegars produced from 'Cranberry' species while those produced form 'Raspberry' species exhibited the highest levels of antioxidant activity (74.43\%). Sensory evaluation based on the 9-point hedonic scales showed that the vinegars produced from 'Mulberry' species displayed the highest overall acceptability with an average score of 7.27, equivalent to the hedonic scale of 9, which indicated the moderately pleasant levels of the vinegar preference of the consumers.
\end{abstract}

Keywords: Antioxidant activity, fermentation, fruit vinegar, berry, sensory evaluation

\section{Introduction}

Due to its availability in several different varieties in every country, vinegar represents one of the most widely used seasonings in the world [1]. In addition to being primarily used as food seasoning, vinegar plays an important role in the production of food products since it is applied in a wide variety of products, including sauces, ketchups and mayonnaise [2]. Moreover, vinegar has long been used in the treatment of many common ailments with claims of anti-infective, antitumor, and antiglycemic properties [3].

The production of vinegar is in general low in costs due to the fact that inexpensive raw materials like by-products from food processing, fruit waste, substandard fruit and agricultural surpluses are utilized [4]. The beneficial effects of vinegar might be due to bioactive substances such as amino acids, organic acids or phenolic compounds derived from its raw materials [5,6]. Moreover, the bioactive compounds in vinegars can be produced and/or increased through the overall vinegar fermentation process [4], where phenolic compounds are transformed into new antioxidative molecules [7]. Additionally, the aroma and flavor of vinegars impacting on consumer acceptance is influenced by the 
http://wjst.wu.ac.th

raw materials used, the compounds formed during the fermentation process, and the fermentation type used [8-11].

Vinegars are the product of scalar fermentation carried out by several groups of microorganisms acting at different moments in time. The initial phase is generally represented by an alcoholic fermentation carried out by yeasts (Saccharomyces cerevisiae). After alcoholic fermentation acetic acid bacteria are the main bacteria at the stage of acetic acid fermentation, which oxidizes ethanol into acetic acid. Several species of acetic acid bacteria such as Acetobacter pasteurianus, A. aceti, A. xylinum and Gluconobacter spp. The most common raw materials are apples, grapes, honey, syrups, cereals, hydrolysed starches, beer and wine [4].

Recently, the demand for fruit vinegars has increased due to their reputation as health food products, which help to promote different kinds of beneficial effects to consumers, such as having antidiabetic effects and lowering cholesterol levels in blood by inhibiting the oxidation of low density lipoproteins (LDLs), among other benefits [2,12]. Owing to its excellent sensorial properties and nutritional compositions having different health-promoting properties, mainly from the antioxidant activities [13], berry is an appealing ingredient for the production of vinegar.

For this purpose, this study was carried out to compare the chemical properties, antioxidant activities and sensory scores of the berry vinegars produced via a 2-stage fermentation process from 4 speciess, namely 'Mulberry', 'Cranberry', 'Rasberry', and 'Blackberry'. In this context, chemical properties were assessed in terms of alcohol contents, glucose and fructose contents, and acetic acid contents. Antioxidant activities were determined by DPPH radical assays and total phenolic contents. Sensory evaluation was performed based on the 9-point hedonic scale.

\section{Materials and methods}

\section{Chemicals and reagents}

2,2-diphenyl-1-picrylhydrazyl hydrate (DPPH) was purchased from Sigma-Aldrich (Steinheim, Germany). gallic acid standard were supplied by Fluka (Buchs, Switzerland) Folin-ciocalteau reagent was from Merck (Darmstadt, Germany) and sodium carbonate (anhydrous) from Univar (Downers Grove, IL, USA). All other chemicals and solvents were purchased from local manufacturers. Deionized water was prepared by a Milli-Q Water Purification system (Millipore, MA, USA).

\section{Material and fermentation}

Berry fruits of 4 species, namely 'Mulberry', 'Cranberry', 'Rasberry', and 'Blackberry, was used for the production of berry vinegars via a 2-stage (alcoholic and acetous) fermentation process. Berry fruits of each species were crushed and mixed with water at a ratio of 1:1 to prepare berry juice. After adjustment of the $\mathrm{pH}$ to 4.5 and sugar content up to $22^{\circ} \mathrm{Brix}$, the berry juice was pasteurized for $30 \mathrm{~min}$ at $60{ }^{\circ} \mathrm{C}$. Alcoholic fermentation was conducted for 7 days at room temperature under static conditions in plastic vessels containing $3 \mathrm{~L}$ of the berry juice inoculated with Lalvin ICV D-47 wine yeast, Saccharomyces cerevisiae, (Wine \& Scientific Equipment Ltd., Part., Ratchaburi, Thailand) at a ratio of $0.75 \%(\mathrm{v} / \mathrm{v})\left(4.24 \times 10^{9} \mathrm{cell} / \mathrm{mL}\right)$. Preparation of yeast inoculum was carried out by mixing $5 \mathrm{~g}$ of yeast powder with $60 \mathrm{~mL}$ of warm water. At the end of the fermentation process, the obtained wine was separated from the sediment by allowing it to settle in glass bottles, followed by pasteurization for $30 \mathrm{~min}$ at $60{ }^{\circ} \mathrm{C}$ and clarification for 45 days at $10^{\circ} \mathrm{C}$. Prior to acetous fermentation, the alcohol content of the obtained wine was adjusted to $7 \%$. Acetous fermentation was performed for 15 days under the aforementioned conditions in glass vessels containing $135 \mathrm{~mL}$ of the berry wine inoculated with Acetobacter pasteurianus TISTR 521 at a ratio of $10 \%(\mathrm{v} / \mathrm{v})$. Sampling was performed at given timepoints to collect the 2-stage fermented berry vinegars by allowing them to settle in microtube and storage at $4{ }^{\circ} \mathrm{C}$ in microtubes before the analyses (Figure 1). 
http://wjst.wu.ac.th

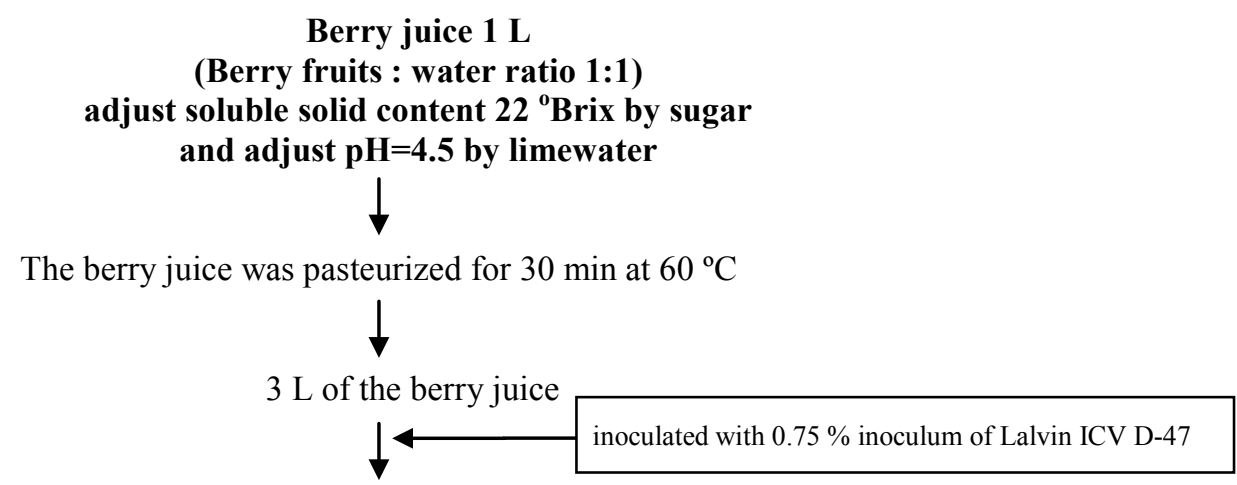

Alcoholic fermentation was conducted for 7 days at room temperature

Berry wine was pasteurized for $30 \mathrm{~min}$ at $60^{\circ} \mathrm{C}$<smiles>[13CH3]</smiles>

The alcohol content of the berry wine was adjusted to $7 \%$<smiles>[3H][3H]</smiles>

$135 \mathrm{~mL}$ of the berry wine

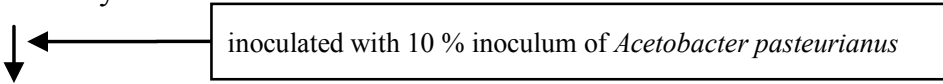

Acetic fermentation was conducted for 15 days at room temperature

Berry vinegar was pasteurized for $30 \mathrm{~min}$ at $60^{\circ} \mathrm{C}$

Figure 1 Schematic diagram of berry vinegar production.

\section{Chemical analysis}

Analysis of alcohol, acetic acid, glucose and fructose contents was performed on a Shimadzu HPLC-RID system (Shimadzu, Japan) consisting of Shimadzu LC-20AD pumps and RID-10A refractive index detector. The analytical column was Aminex HPX-87H column $(300 \mathrm{~mm} \times 7.8 \mathrm{~mm}$ i.d., $9 \mu \mathrm{m}$, BioRad Laboratories, Inc., USA) coupled to a cationic exchange precolumn (Bio-Rad Laboratories, Inc., USA). $\mathrm{H}_{2} \mathrm{SO}_{4}(5 \mathrm{mM})$ was used as the mobile phase. The injection volume was $20 \mathrm{~mL}$ with a flow rate of $0.6 \mathrm{~mL} / \mathrm{min}$. The column temperature was set at $45^{\circ} \mathrm{C}$.

\section{Total phenolic contents}

Total phenolic contents of the berry vinegars were determined using Folin-Ciocalteu reagent as described by [14]. Briefly, $1 \mathrm{~mL}$ of each sample was diluted with $9.5 \mathrm{~mL}$ of distilled water and was then mixed with $0.5 \mathrm{~mL}$ of Folin-Ciocalteu reagent and $2 \mathrm{~mL}$ of $10 \% \mathrm{Na}_{2} \mathrm{CO}_{3}$ solution. After 30-min incubation at room temperature, absorbance was measured at $765 \mathrm{~nm}$ using a Shimadzu UV-1700 spectrophotometer (Shimadzu, Japan). Results were expressed as $\mathrm{mg}$ gallic acid equivalents in $1 \mathrm{~mL}$ of sample (mg GAE/mL).

\section{DPPH radical-scavenging activity}

Antioxidant activities of the vinegars were evaluated by DPPH radical assay [15], in which 2,2diphenyl-1-picrylhydrazyl hydrate (DPPH) radical was used as a stable radical. In brief, $1.5 \mathrm{~mL}$ of each sample was added to $1.5 \mathrm{~mL}$ of $0.1 \mathrm{mM}$ DPPH radical solution prepared in ethanol, and the mixture was 
http://wjst.wu.ac.th

incubated for $20 \mathrm{~min}$ at room temperature in the dark. After incubation, absorbance was measured at 517 nm using a Shimadzu UV-1700 spectrophotometer (Shimadzu, Japan), and the DPPH radical scavenging activities were expressed as the percentage of the DPPH radical elimination effect of vitamin C. Control solutions were prepared by dissolving $0.004 \mathrm{~g}$ of DPPH in $95 \%$ ethanol, followed by adjustment of the solutions to a final volume of $100 \mathrm{~mL}$. DPPH radical scavenging capacity (RSC) was calculated using the equation $\% \mathrm{RSC}=\left(A_{\mathrm{C}}-A_{\mathrm{S}} / A_{\mathrm{C}}\right) \times 100$, where $A_{\mathrm{C}}$ and $A_{\mathrm{S}}$ denote the absorbance of control and sample, respectively.

\section{Sensory analysis}

About $200 \mathrm{~mL}$ of the berry vinegars were mixed with $150 \mathrm{~mL}$ of honey and $150 \mathrm{~mL}$ of water to make drinking vinegars and the obtained drinking vinegars were subjected to the sensory evaluation based on the 9-point hedonic scale by using 30 untrained panelists. The panelists were asked to rank the 9-point scale of affective tests of sweet, color, odor, taste and overall acceptance with the scale 9 representing like extremely, 5 representing neither like nor dislike and 1 representing dislike extremely.

\section{Statistical analysis}

A randomized block design, with 3 replicates and 4 samples per replicate, was used to compare the chemical properties, antioxidant activities total phenolic contents and consumers' preference of the berry vinegars produced from 4 berry species. The results are expressed as the mean \pm one standard deviation (SD) of 3 replicates and data were analyzed using one-way analysis of variance (ANOVA) with Duncan's multiple range test (DMRT) to determine the significance between samples. In all cases, $p<0.05$ was considered significant.

\section{Results and discussion}

\section{Chemical properties of the berry wines and vinegars}

The berry wines produced from 4 berry species via a 7-day alcoholic fermentation process using Saccharomyces cerevisiae as an inoculant were analyzed for their chemical compositions, and the results are presented in Table 1. It was observed that at the end of the fermentation, high alcohol content was detected in all the berry wines, indicating that sugars in the berry juice were rapidly converted to alcohol. The berry wine produced from 'Blackberry' species contained the highest alcohol content of $11.73 \%$, which was much greater than that $(9.45 \%)$ detected in the mulberry wines which was produced from Longsang variety [16].

As given in Table 2, Glucose was rapidly utilized during the production of the berry wine as observed for all samples, with the most rapidly utilized glucose observed after 1 day of the fermentation in 'Rasberry' species. Notably, glucose was completely depleted in Rasberry and Blackberry wine samples after 5 days Mulberry wine samples after 6 days of the fermentation. Fructose was likely to be utilized more slowly as compared to glucose (Table 3). Again, the most rapidly utilized fructose was observed in the berry wine produced from 'Rasberry' species which was completely depleted after 5 days of the fermentation. Meanwhile, fructose was completely depleted in Mulberry and Blackberry wine samples after 7 days of the fermentation. The rapid utilization of glucose and fructose and the consequent increase in the levels of alcohol confirmed that the yeast dominated the fermentation, which was supported by an earlier study [17] which elucidated the rapid utilization of glucose and fructose in the production of durian wine, in which at the end of the fermentation fructose was completely depleted while glucose remained at $0.046 \mathrm{~g} / 100 \mathrm{~mL}$.

During alcoholic fermentation, hexose sugars in berry must is metabolized to pyruvate via the glycolytic pathway, which is then decarboxylated to acetaldehyde and finally reduced to ethanol. Glucose and fructose are the preferred sugars of $S$. cerevisiae. When glucose is present, a wide range of genes involved in utilizing alternative carbon sources are repressed, but fructose utilization is not repressed [18]. Glucose and fructose can be consumed at the same time by yeast, although glucose utilization is faster than fructose utilization. S. cerevisiae is a glucophilic yeast, displaying a preference for utilizing glucose. Even though fructose is used along with glucose, the latter is depleted first, giving rise to the discrepancy 
between the amounts of sugars consumed during fermentation. This preference results in a difference in consumption profiles. Consequently the residual sugar left after the completion of fermentation contains more fructose than glucose.

During an 15-day acetous fermentation process, the berry vinegars produced from the 4 berry wines using A. pasteurianus were analyzed for their chemical compositions, and the results are given in Table 4. As illustrated in Table 4, all the berry vinegars showed a significant decrease in the alcohol content as it was converted to acetic acid by acetic acid bacteria, which was consistent with the increased acetic acid content, as depicted in Table 5. However, the alcohols were not completely depleted, in which at the end of acetous fermentation the vinegar produced from 'Mulberry' species contained the highest alcohol content of $0.89 \pm 0.03 \%$ while that produced from 'Blackberry' species was completely depleted, which was in agreement with an earlier study [19] which elucidated that the alcohol content in the Hericium erinaceus vinegar was $0 \%$ after 9 days of acetic fermentation. On the acetous fermentation, at the end of a 15 -day acetous fermentation process, acetic acid content was found to range from $3.96 \%$ to $5.01 \%$, with the highest value of $5.01 \pm 0.01 \%$ observed in the berry vinegar produced from 'Cranberry' species and the lowest $3.96 \pm 0.00 \%$ in that produced from 'Mulberry' species (Table 5), which was much lower than that obtained in a previous study [20], in which an acetic acid content of $5.5 \%$ was detected in the strawberry vinegar after 80 days of acetous fermentation. Glucose and fructose contents in Tables 6 and 7 showed that Cranberry vinegar had the highest sugar contents in day 15 of fermentation. (3.67 and $12.15 \%$, respectively), our result revealed that alcohol fermentation of cranberry wine had problem about yeast survival which made the sugar remain in acetous fermentation. In the production of vinegar the concentrations of both the ethanol and the final metabolic product (acetic acid) must be controlled and maintained within certain limits as an excess in ethanol concentration will inhibit bacterial growth. Moreover, the absence of ethanol leads to the death of part of the culture and acetate peroxidation may occur when the bacteria use acetic acid as a carbon source for leading to the formation of $\mathrm{CO}_{2}$ and $\mathrm{H}_{2} \mathrm{O}$. Oxygen supply must be maintained between certain limits throughout the process as Acetobacter species are strict aerobic microorganisms and an interruption in oxygen supply may result in the death of the culture [21].

Table 1 Changes in alcohol contents of the 4 berry wines produced via a 2-stage fermentation process.

\begin{tabular}{|c|c|c|c|c|c|c|c|}
\hline \multirow{3}{*}{ Species } & \multicolumn{7}{|c|}{ Alcohol content (\%) } \\
\hline & \multicolumn{7}{|c|}{ Days after fermentation } \\
\hline & 1 & 2 & 3 & 4 & 5 & 6 & 7 \\
\hline Mulberry & $2.52 \pm 0.01^{b}$ & $5.18 \pm 0.01^{b}$ & $8.04 \pm 0.03^{b}$ & $8.83 \pm 0.00^{b}$ & $10.37 \pm 0.01^{\mathrm{b}}$ & $10.46 \pm 0.05^{b}$ & $11.37 \pm 0.03^{b}$ \\
\hline Cranberry & $0.62 \pm 0.11^{d}$ & $1.43 \pm 0.02^{\mathrm{d}}$ & $2.30 \pm 0.00^{\mathrm{d}}$ & $3.24 \pm 0.02^{\mathrm{d}}$ & $4.15 \pm 0.13^{c}$ & $4.87 \pm 0.11^{\mathrm{c}}$ & $5.72 \pm 0.08^{\mathrm{c}}$ \\
\hline Rasberry & $2.80 \pm 0.00^{\mathrm{a}}$ & $6.57 \pm 0.01^{\mathrm{a}}$ & $8.98 \pm 0.01^{\mathrm{a}}$ & $10.26 \pm 0.01^{\mathrm{a}}$ & $10.47 \pm 001^{\mathrm{b}}$ & $10.72 \pm 0.04^{\mathrm{b}}$ & $11.49 \pm 0.04^{b}$ \\
\hline Blackberry & $1.14 \pm 0.08^{\mathrm{c}}$ & $4.01 \pm 0.00^{\mathrm{c}}$ & $7.20 \pm 0.01^{\mathrm{c}}$ & $9.17 \pm 0.01^{\mathrm{c}}$ & $11.35 \pm 0.01^{\mathrm{a}}$ & $11.18 \pm 0.39^{\mathrm{a}}$ & $11.73 \pm 0.01^{\mathrm{a}}$ \\
\hline
\end{tabular}

Values with different letters in the same column are significantly different according to Duncan's multiple range test $(p<0.05)$.

Table 2 Changes in glucose contents of the 4 berry wines produced via a 2-stage fermentation process.

\begin{tabular}{|c|c|c|c|c|c|c|c|}
\hline \multirow{3}{*}{ Species } & \multicolumn{7}{|c|}{ Glucose content (\%) } \\
\hline & \multicolumn{7}{|c|}{ Days after fermentation } \\
\hline & 1 & 2 & 3 & 4 & 5 & 6 & 7 \\
\hline Mulberry & $5.92 \pm 0.01^{b}$ & $3.69 \pm 0.00^{\mathrm{c}}$ & $1.99 \pm 0.01^{\mathrm{c}}$ & $0.45 \pm 0.01^{\mathrm{b}}$ & $0.09 \pm 0.01^{b}$ & $0.00 \pm 0.00^{b}$ & $0.00 \pm 0.00^{b}$ \\
\hline Cranberry & $8.63 \pm 0.04^{\mathrm{a}}$ & $7.82 \pm 0.06^{\mathrm{a}}$ & $6.68 \pm 0.02^{\mathrm{a}}$ & $4.38 \pm 0.03^{\mathrm{a}}$ & $5.39 \pm 0.23^{\mathrm{a}}$ & $3.46 \pm 0.01^{\mathrm{a}}$ & $2.81 \pm 0.00^{\mathrm{a}}$ \\
\hline Rasberry & $5.41 \pm 0.01^{\mathrm{c}}$ & $3.20 \pm 0.01^{\mathrm{d}}$ & $1.20 \pm 0.01^{\mathrm{d}}$ & $0.05 \pm 0.01^{\mathrm{d}}$ & $0.00 \pm 0.00^{\mathrm{b}}$ & $0.00 \pm 0.00^{\mathrm{b}}$ & $0.00 \pm 0.00^{\mathrm{b}}$ \\
\hline Blackberry & $8.61 \pm 0.01^{\mathrm{a}}$ & $4.94 \pm 0.01^{b}$ & $2.06 \pm 0.01^{\mathrm{b}}$ & $0.35 \pm 0.01^{\mathrm{c}}$ & $0.00 \pm 0.00^{\mathrm{b}}$ & $0.00 \pm 0.00^{\mathrm{b}}$ & $0.00 \pm 0.00^{\mathrm{b}}$ \\
\hline
\end{tabular}

Values with different letters in the same column are significantly different according to Duncan's multiple range test $(p<0.05)$. 
Table 3 Changes in fructose contents of the 4 berry wines produced via a 2-stage fermentation process.

\begin{tabular}{llllllll}
\hline & \multicolumn{7}{c}{ Fructose content (\%) } \\
\cline { 2 - 7 } Species & \multicolumn{7}{c}{ Days after fermentation } \\
\cline { 2 - 8 } & $\mathbf{1}$ & $\mathbf{2}$ & $\mathbf{3}$ & $\mathbf{5}$ & $\mathbf{6}$ & $\mathbf{7}$ \\
\hline Mulberry & $14.99 \pm 0.06^{\mathrm{c}}$ & $10.06 \pm 0.01^{\mathrm{c}}$ & $6.77 \pm 0.04^{\mathrm{c}}$ & $2.13 \pm 0.00^{\mathrm{c}}$ & $0.94 \pm 0.05^{\mathrm{b}}$ & $0.13 \pm 0.04^{\mathrm{b}}$ & $0.00 \pm 0.00^{\mathrm{b}}$ \\
Cranberry & $17.71 \pm 0.61^{\mathrm{b}}$ & $16.98 \pm 0.27^{\mathrm{a}}$ & $16.01 \pm 0.01^{\mathrm{a}}$ & $15.73 \pm 0.05^{\mathrm{a}}$ & $14.44 \pm 0.17^{\mathrm{a}}$ & $13.94 \pm 0.12^{\mathrm{a}}$ & $12.72 \pm 0.07^{\mathrm{a}}$ \\
Rasberry & $12.23 \pm 0.01^{\mathrm{d}}$ & $7.07 \pm 0.01^{\mathrm{d}}$ & $2.72 \pm 0.01^{\mathrm{d}}$ & $0.84 \pm 0.01^{\mathrm{d}}$ & $0.00 \pm 0.00^{\mathrm{d}}$ & $0.00 \pm 0.00^{\mathrm{b}}$ & $0.00 \pm 0.00^{\mathrm{b}}$ \\
Blackberry & $19.01 \pm 0.08^{\mathrm{a}}$ & $14.79 \pm 0.05^{\mathrm{b}}$ & $8.01 \pm 0.01^{\mathrm{b}}$ & $2.35 \pm 0.01^{\mathrm{b}}$ & $0.46 \pm 0.02^{\mathrm{c}}$ & $0.00 \pm 0.00^{\mathrm{b}}$ & $0.00 \pm 0.00^{\mathrm{b}}$ \\
\hline
\end{tabular}

Values with different letters in the same column are significantly different according to Duncan's multiple range test $(p<0.05)$.

Table 4 Changes in alcohol contents of the 4 berry vinegars produced via a 2 -stage fermentation process.

\begin{tabular}{lllll}
\hline \multirow{2}{*}{ Species } & \multicolumn{4}{c}{ Alcohol content (\%) } \\
\cline { 2 - 4 } & \multicolumn{4}{c}{ Days after fermentation } \\
\cline { 2 - 4 } & $\mathbf{0}$ & $\mathbf{5}$ & $\mathbf{1 0}$ & $\mathbf{1 5}$ \\
\hline Mulberry & $6.60 \pm 0.53^{\mathrm{ab}}$ & $3.51 \pm 0.02^{\mathrm{b}}$ & $1.96 \pm 0.02^{\mathrm{b}}$ & $0.89 \pm 0.03^{\mathrm{a}}$ \\
Cranberry & $5.48 \pm 0.02^{\mathrm{c}}$ & $2.30 \pm 0.03^{\mathrm{c}}$ & $0.43 \pm 0.02^{\mathrm{d}}$ & $0.16 \pm 0.20^{\mathrm{bc}}$ \\
Rasberry & $6.98 \pm 0.00^{\mathrm{a}}$ & $4.57 \pm 0.04^{\mathrm{a}}$ & $2.14 \pm 0.07^{\mathrm{a}}$ & $0.31 \pm 0.01^{\mathrm{b}}$ \\
Blackberry & $6.03 \pm 0.01^{\mathrm{bc}}$ & $3.44 \pm 0.07^{\mathrm{b}}$ & $0.91 \pm 0.02^{\mathrm{c}}$ & $0.00 \pm 0.00^{\mathrm{d}}$ \\
\hline
\end{tabular}

Values with different letters in the same column are significantly different according to Duncan's multiple range test $(p<0.05)$.

Table 5 Changes in acetic acid contents of the 4 berry vinegars produced via a 2-stage fermentation.

\begin{tabular}{|c|c|c|c|c|}
\hline \multirow{3}{*}{ Species } & \multicolumn{4}{|c|}{ Acetic acid contents (\%) } \\
\hline & \multicolumn{4}{|c|}{ Days after fermentation } \\
\hline & $\mathbf{0}$ & 5 & 10 & 15 \\
\hline Mulberry & $0.06 \pm 0.00^{c}$ & $2.07 \pm 0.02^{b}$ & $3.26 \pm 0.00^{b}$ & $3.96 \pm 0.00^{\mathrm{c}}$ \\
\hline Cranberry & $0.07 \pm 0.00^{c}$ & $3.22 \pm 0.01^{\mathrm{a}}$ & $4.95 \pm 0.06^{\mathrm{a}}$ & $5.01 \pm 0.01^{\mathrm{a}}$ \\
\hline Rasberry & $0.13 \pm 0.00^{\mathrm{b}}$ & $0.84 \pm 0.00^{\mathrm{d}}$ & $3.21 \pm 0.04^{b}$ & $4.74 \pm 0.00^{\mathrm{b}}$ \\
\hline Blackberry & $0.15 \pm 0.01^{\mathrm{a}}$ & $1.58 \pm 0.08^{\mathrm{c}}$ & $3.09 \pm 0.01^{\mathrm{c}}$ & $4.72 \pm 0.04^{\mathrm{b}}$ \\
\hline
\end{tabular}

Values with different letters in the same column are significantly different according to Duncan's multiple range test $(p<0.05)$. 
http://wjst.wu.ac.th

Table 6 Changes in Glucose contents of the 4 berry vinegars produced via a 2-stage fermentation.

\begin{tabular}{lllll}
\hline \multirow{2}{*}{ Species } & \multicolumn{4}{c}{ Glucose contents (\%) } \\
\cline { 2 - 5 } & \multicolumn{4}{c}{ Days after fermentation } \\
\cline { 2 - 4 } & $\mathbf{0}$ & $\mathbf{5}$ & $\mathbf{1 0}$ & $\mathbf{1 5}$ \\
\hline Mulberry & $0.00 \pm 0.00^{\mathrm{b}}$ & $0.08 \pm 0.02^{\mathrm{c}}$ & $0.33 \pm 0.00^{\mathrm{b}}$ & $0.35 \pm 0.01^{\mathrm{b}}$ \\
Cranberry & $3.62 \pm 0.05^{\mathrm{a}}$ & $3.65 \pm 0.00^{\mathrm{a}}$ & $3.69 \pm 0.01^{\mathrm{a}}$ & $3.67 \pm 0.01^{\mathrm{a}}$ \\
Rasberry & $0.00 \pm 0.00^{\mathrm{b}}$ & $0.23 \pm 0.00^{\mathrm{b}}$ & $0.23 \pm 0.00^{\mathrm{bc}}$ & $0.27 \pm 0.03^{\mathrm{c}}$ \\
Blackberry & $0.00 \pm 0.00^{\mathrm{b}}$ & $0.10 \pm 0.00^{\mathrm{c}}$ & $0.17 \pm 0.08^{\mathrm{c}}$ & $0.19 \pm 0.00^{\mathrm{d}}$ \\
\hline
\end{tabular}

Values with different letters in the same column are significantly different according to Duncan's multiple range test $(p<0.05)$.

Table 7 Changes in Fructose contents of the 4 berry vinegars produced via a 2-stage fermentation.

\begin{tabular}{lllll}
\hline \multirow{2}{*}{ Species } & \multicolumn{3}{c}{ Fructose contents (\%) } \\
\cline { 2 - 4 } & \multicolumn{4}{c}{ Days after fermentation } \\
\cline { 2 - 4 } & $\mathbf{0}$ & $\mathbf{5}$ & $\mathbf{1 0}$ & $\mathbf{1 5}$ \\
\hline Mulberry & $0.00 \pm 0.00^{\mathrm{b}}$ & $0.00 \pm 0.00^{\mathrm{b}}$ & $0.00 \pm 0.00^{\mathrm{b}}$ & $0.00 \pm 0.00^{\mathrm{b}}$ \\
Cranberry & $13.48 \pm 0.13^{\mathrm{a}}$ & $12.74 \pm 0.00^{\mathrm{a}}$ & $12.61 \pm 0.04^{\mathrm{a}}$ & $12.15 \pm 0.02^{\mathrm{a}}$ \\
Rasberry & $0.00 \pm 0.00^{\mathrm{b}}$ & $0.00 \pm 0.00^{\mathrm{b}}$ & $0.00 \pm 0.00^{\mathrm{b}}$ & $0.00 \pm 0.00^{\mathrm{b}}$ \\
Blackberry & $0.00 \pm 0.00^{\mathrm{b}}$ & $0.00 \pm 0.00^{\mathrm{b}}$ & $0.00 \pm 0.00^{\mathrm{b}}$ & $0.00 \pm 0.00^{\mathrm{b}}$ \\
\hline
\end{tabular}

Values with different letters in the same column are significantly different according to Duncan's multiple range test $(p<0.05)$.

Total phenolic contents and antioxidant activities

The levels of antioxidant activities of the berry vinegars are presented in Table 8. The results showed that the berry wine derived from 'Mulberry' species exhibited the highest antioxidant activity of $60.85 \pm 0.21 \%$, which was greater than that produced from citrus fruit $(36.8 \pm 0.09 \%)$ [12]. On the other hand, the vinegar produced from 'Rasberry' species was observed to exhibit the highest antioxidant activity of $74.43 \pm 0.74 \%$, which was much greater than that detected in the purple sweet potato makgeolli vinegar (67.63 $\pm 0.17 \%$ ) [22]. Raspberries (Rubus idaeus L.) contain high levels of polyphenolic phytochemicals, particularly flavonoids and anthocyanin pigments, which give raspberries their characteristic color. The phytochemicals in raspberries might have a significant antioxidant activity and act as a protectant against biological oxidative stress in mammalian cells [23].

The levels of total phenolic contents detected in the berry vinegars produced from different berry speciess via a 2-stage fermentation process are given in Table 9. It was noted that the berry wine derived from 'Cranberry' species contained the highest levels $(518.26 \pm 11.25 \mathrm{mg} / \mathrm{L})$ of total phenolics. Similar results were observed for the berry wine produced from the same species, in which the vinegar measured at the end of acetous fermentation exhibited the highest total phenolic content of $250.02 \pm 24.19 \mathrm{mg} / \mathrm{L}$, which was much lower than that detected in the strawberry vinegar $(683 \pm 10 \mathrm{mg} / \mathrm{kg})$ [24].

Cranberries was found rich in vitamin $\mathrm{C}$, organic acids, polyphenols (include anthocyanins flavonoid, phenolic acids and proanthocyanidins (condensed tannin). Flavonoids and anthocyanins of cranberry showed anticancer and antioxidant and previous study [25] show cranberry vinegar could provide the prevention of cardiovascular disease and increase the antioxidation of human body. 
http://wjst.wu.ac.th

\section{Sensory evaluation}

The levels of consumers' acceptability based on the 9-point hedonic scale of the drinking vinegars, a blend of the vinegars made from different berry species and honey, are depicted in Table 10. The results showed that significant $(p<0.05)$ differences in color was observed among the drinking vinegars produced from different berry speciess. 'Rasberry' species displayed the highest level of color consumers' preference $(7.40 \pm 1.38)$. The drinking vinegar produced from 'Mulberry' species displayed the highest level of consumers' preference, with the mean overall acceptability score of $7.27 \pm 1.78$, which was much greater than that detected in the cooked strawberry must vinegar (6.50) [26]. The 9-point hedonic scale has been the primary method of hedonic scaling in food science, which has been widely used for assessment of consumers' acceptability of foods and drinks [27]. In our study, the high levels of consumers' preference of drinking berry vinegars might be attributed to the addition of honey, which was well supported by an earlier study [28] which elucidated that the addition of dietary fiber derived from citrus fruits enhanced the phenolic and volatile profile as well as the judges' preference of the vinegar.

Table 8 Antioxidant activities of the 4 berry vinegars produced via a 2-stage fermentation process.

\begin{tabular}{lcc}
\hline \multirow{2}{*}{ Species } & \multicolumn{2}{c}{ DPPH (\% inhibition) } \\
\cline { 2 - 3 } & Wine & Vinegar \\
\hline Mulberry & $60.85 \pm 0.21^{\mathrm{a}}$ & $25.25 \pm 2.76^{\mathrm{d}}$ \\
Cranberry & $27.50 \pm 0.71^{\mathrm{d}}$ & $30.89 \pm 7.46^{\mathrm{c}}$ \\
Rasberry & $50.33 \pm 0.00^{\mathrm{c}}$ & $74.43 \pm 0.74^{\mathrm{a}}$ \\
Blackberry & $52.15 \pm 0.78^{\mathrm{b}}$ & $72.62 \pm 4.72^{\mathrm{b}}$ \\
\hline
\end{tabular}

Values with different letters in the same column are significantly different according to Duncan's multiple range test $(p<0.05)$.

Table 9 Total phenolic contents of the 4 berry vinegars produced via a 2-stage fermentation process.

\begin{tabular}{lcc}
\hline \multirow{2}{*}{ Species } & \multicolumn{2}{c}{ Total phenolic content (mg/L) } \\
\cline { 2 - 3 } & Wine & Vinegar \\
\hline Mulberry & $455.20 \pm 15.55^{\mathrm{b}}$ & $190.11 \pm 22.05^{\mathrm{b}}$ \\
Cranberry & $518.26 \pm 11.25^{\mathrm{a}}$ & $250.02 \pm 24.19^{\mathrm{a}}$ \\
Rasberry & $391.73 \pm 17.19^{\mathrm{c}}$ & $181.37 \pm 13.51^{\mathrm{c}}$ \\
Blackberry & $336.05 \pm 3.94^{\mathrm{d}}$ & $167.50 \pm 2.20^{\mathrm{d}}$ \\
\hline
\end{tabular}

Values with different letters in the same column are significantly different according to Duncan's multiple range test $(p<0.05)$.

Table 10 Sensory scores of the drinking vinegars blended from the 4 fermented berry vinegars.

\begin{tabular}{llllll}
\hline Species & Sweet & Color & Odor & Taste & Overall acceptability \\
\hline Mulberry & $6.63 \pm 1.75$ & $7.23 \pm 1.04^{\mathrm{a}}$ & $6.27 \pm 1.74$ & $7.07 \pm 1.36$ & $7.27 \pm 1.78$ \\
Cranberry & $6.27 \pm 1.89$ & $5.93 \pm 1.53^{\mathrm{b}}$ & $6.27 \pm 1.91$ & $6.40 \pm 1.96$ & $6.80 \pm 1.85$ \\
Rasberry & $5.93 \pm 1.74$ & $7.40 \pm 1.38^{\mathrm{a}}$ & $6.17 \pm 1.78$ & $6.53 \pm 1.48$ & $7.17 \pm 1.36$ \\
Blackberry & $6.47 \pm 1.36$ & $6.73 \pm 1.70^{\mathrm{a}}$ & $6.20 \pm 2.33$ & $7.27 \pm 1.28$ & $6.97 \pm 1.67$ \\
\hline
\end{tabular}

Values with different letters in the same column are significantly different according to Duncan's multiple range test $(p<0.05)$. 
http://wjst.wu.ac.th

\section{Conclusions}

This study has compared the levels of acetic acid, total phenolics, antioxidants and consumers' preference of the berry vinegars produced from 4 berry speciess via a 2-stage fermentation process. Our results showed that the vinegars produced from 'Cranberry' species exhibited the highest level of acetic acid $(5.01 \%)$ while those produced from 'Rasberry' species displayed the highest antioxidant activities $(74.43 \%)$ measured by means of DPPH radical assay. Meanwhile, the vinegars produced from 'Cranberry' species were observed to have the highest total phenolics $(250.02 \mathrm{mg} / \mathrm{L})$. Sensory evaluation based on the 9-point hedonic scale using untrained panelists showed that the drinking vinegars made from 'Mulberry' species had the highest overall acceptability (7.27). Our findings suggest that the vinegars produced form 'Rasberry', 'Cranberry' and 'Mulberry' speciess could be used as health-promoting drinks.

\section{Acknowledgements}

This work was supported by a grant from Rajabhat Mahasarakham University. The authors would like to thank the laboratory equipment center of Mahasarakham University for the laboratory facilities.

\section{References}

[1] D Jo, GR Kim, SH Yeo, YJ Jeong, BS Noh and JH Kwon. Analysis of aroma compounds of commercial cider vinegars with different acidities using SPME/GC-MS, electronic nose, and sensory evaluation. Food Sci. Biotech. 2013; 22, 1559-65.

[2] CW Ho, AM Lazim, S Fazry, UKHH Zaki and S Lim. Varieties, production, composition and health benefits of vinegars: A review. Food Chem. 2017; 221, 1621-30.

[3] CS Johnston and CA Gaas. Vinegar: Medicinal uses and antiglycemic effect. Medsc. Gen. Med. 2006; 8, 61-1.

[4] L Solieri and P Giudici. Vinegars of the World. In: L Solieri and P Giudici (Eds.). Vinegars of the World. Springer Milan, Milano, Italia, 2009, p. 1-16.

[5] NH Budak, E Aykin, AC Seydim, AK Greene and ZB Guzel-Seydim. Functional properties of vinegar. J. Food Sci. 2014; 79, 757-64.

[6] PR Ghosh, D Fawcett, SB Sharma and GE Poinern. Progress towards sustainable utilisation and management of food wastes in the global economy. Int. J. Food Sci. 2016; 2016, 3563478.

[7] F Shahidi, J McDonald, A Chandrasekara and Y Zhong. Phytochemicals of foods, beverages and fruit vinegars: Chemistry and health effects. Asia Pac. J. Clin. Nutr. 2008; 17, 380-2.

[8] RM Callejon, ML Morales, AC Ferreira and AM Troncoso. Defining the typical aroma of sherry vinegar: Sensory and chemical approach. J. Agr. Food Chem. 2008; 56, 8086-95.

[9] J Liang, J Xie, L Hou, M Zhao, J Zhao, J Cheng, S Wang and BG Sun. Aroma constituents in Shanxi aged vinegar before and after aging. J. Agr. Food Chem. 2016; 64, 7597-605.

[10] ML Morales, W Tesfaye, MC Garcia-Parrilla, JA Casas and AM Troncoso. Evolution of the aroma profile of sherry wine vinegars during an experimental aging in wood. J. Agr. Food Chem. 2002; 50, 3173-8.

[11] C Ubeda, RM Callejón, AM Troncoso, JM Moreno-Rojas, F Peña and ML Morales. Characterization of odour active compounds in strawberry vinegars. Flavour Fragrance J. 2012; 27, 313-21.

[12] Y Chen, Y Huang, Y Bai, C Fu, M Zhou, B Gao, C Wang, D Li, Y Hu and N Xu. Effects of mixed cultures of Saccharomyces cerevisiae and Lactobacillus plantarum in alcoholic fermentation on the physicochemical and sensory properties of citrus vinegar. LWT Food Sci. Tech. 2017; 84, 753-63.

[13] Y Kim, AJ Lounds-Singleton and ST Talcott. Antioxidant phytochemical and quality changes associated with hot water immersion treatment of berries (Mangifera indica L.). Food Chem. 2009; 115, 989-93.

[14] VL Singleton, R Orthofer and RM Lamuela-Raventós. Analysis of total phenols and other oxidation substrates and antioxidants by means of Folin-Ciocalteu reagent. Meth. Enzymol. 1999; 299, 152-78. 
http://wjst.wu.ac.th

[15] W Brand-Williams, ME Cuvelier and C Berset. Use of a free radical method to evaluate antioxidant activity. LWT Food Sci. Tech. 1995; 28, 25-30.

[16] L Wang, X Sun, F Li, D Yu, X Liu, W Huang and J Zhan. Dynamic changes in phenolic compounds, colour and antioxidant activity of mulberry wine during alcoholic fermentation. $J$. Funct. Food 2015; 18, 254-65.

[17] F Taniasuri, PR Lee and SQ Liu. Induction of simultaneous and sequential malolactic fermentation in durian wine. Int. J. Food Microbiol. 2016; 230, 1-9.

[18] J Dynesen, H Smits, L Olsson and J Nielsen. Carbon catabolite repression of invertase during batch cultivations of Saccharomyces cerevisiae: The role of glucose, fructose, and mannose. Appl. Microbiol. Biotech. 1998; 50, 579-82.

[19] T Li, YM Lo and B Moon. Feasibility of using Hericium erinaceus as the substrate for vinegar fermentation. LWT Food Sci. Tech. 2014; 55, 323-8.

[20] C Hidalgo, MJ Torija, A Mas and E Mateo. Effect of inoculation on strawberry fermentation and acetification processes using native strains of yeast and acetic acid bacteria. Food Microbiol. 2013; 34, 88-94.

[21] W Tesfaye, MC García-Parrilla and AM Troncoso. Set up and optimization of a laboratory scale fermentor for the production of wine vinegar. J. Inst. Brew. 2000; 106, 215-9.

[22] JE Chun, MY Baik and BY Kim. Manufacture and quality evaluation of purple sweet potato Makgeolli vinegar using a 2-stage fermentation. Food Sci. Biotech. 2014; 23, 1145-9.

[23] UB Jagtap and VA Bapat. Wines from fruits other than grapes: Current status and future prospectus. Foodbioscience 2015; 9, 80-96.

[24] C Ubeda, RM Callejón, C Hidalgo, MJ Torija, AM Troncoso and ML Morales. Employment of different processes for the production of strawberry vinegars: Effects on antioxidant activity, total phenols and monomeric anthocyanins. LWT Food Sci. Tech. 2013; 52, 139-45.

[25] CK Wang, HY Fu and M Chiang. Cardiovascular disease preventation of cranberry vinegar. Nutr. Sci. J. 2007; 32, 129-32

[26] C Ubeda, RM Callejón, AM Troncoso and ML Morales. Consumer acceptance of new strawberry vinegars by preference mapping. Int. J. Food Prop. 2017; 20, 2760-71.

[27] AV Cardello. Hedonic scaling: Assumptions, contexts and frames of reference. Curr. Opin. Food Sci. 2017; 15, 14-21.

[28] A Marrufo-Curtido, MJ Cejudo-Bastante, MC Rodríguez-Dodero, R Natera-Marín, R CastroMejías, C García-Barroso and E Durán-Guerrero. Novel vinegar-derived product enriched with dietary fiber: Effect on polyphenolic profile, volatile composition and sensory analysis. J. Food Sci. Tech. 2015; 52, 7608-24. 